\title{
Jacques Richard*
}

\section{The Need to Reform the Dangerous IFRS System of Accounting}

https://doi.org/10.1515/ael-2017-0017

Published online October 3, 2017

Abstract: As a fundamental instrument of financial capitalism the today's IFRS system of accounting is not only totally unsuitable for the needs of a new ecological world but also represents a serious menace for the development of a sound economic system. The goal of this article is to explain the main reasons for this criticism and to suggest some elements of reconstruction of the today's accounting system with a new international environmental accounting to be promoted by the European Union.

Keywords: international accounting, international company law

\section{Table of contents}

1 The dangerous evolution of financial accounting towards the IFRS

2 Official and real reasons for the evolution towards IFRS

3 The main problems with the IFRS and the solutions

4 General conclusion References

Accounting for the European Private Sector: Reconsidering Accounting Objectives for Economy and Finance

1. “Accounting for Europe's Economy and Society: Considerations for Financial Stability, Economic Development and the Public Good" by Yuri Biondi, https://doi.org/10.1515/ael2017-0018

2. "On the Accounting Regulation for the European Private Sector" by Arnaldo Canziani, https://doi.org/10.1515/ael-2017-0015

3. "The Need to Reform the Dangerous IFRS System of Accounting" by Jacques Richard, https://doi.org/10.1515/ael-2017-0017

4. "International Financial Reporting Standards (IFRS): Stress Testing in Financialized Reporting Entities" by Colin Haslam, https://doi.org/10.1515/ael-2017-0016

5. "Open Debate on Accounting for the European Private Sector" by Imke Graeff, https://doi. org/10.1515/ael-2017-0024

*Corresponding author: Jacques Richard, Autorité des Normes Comptables (ANC) Committee, Dauphine University of Paris, Paris, France, E-mail: jacques.richard17@laposte.net 
Thank you very much for inviting me to this debate. I will speak about the current state of financial accounting in Europe, using an historical perspective. The plan of my speech is divided into three parts: First part: The dangerous evolution of the European financial accounting towards IFRS; second part: The false and real reasons of this evolution towards IFRS; and third part: Proposals of reforms.

\section{The dangerous evolution of financial accounting towards the IFRS}

To illustrate this evolution I will take the example of a fruit tree plantation, but with a simplified timing of exploitation reduced to only two symbolic periods one and two. Of course, normally, the period should be of about twenty years or more. But I need to shorten it for reasons of time and simplicity. At the very beginning the farmer buys seeds and plants trees and has to pay for that 1000 (the unit of account is not important) as initial outlays. During the periods one and two there is a progressive maturation of the trees and at the end of period two the farmer expects to sell the fruits for a global net amount of 1331 after deduction of normal wages of salaried people. The expected profit is then 331 for the whole period. Let us see and compare what are the accounting data in the course of the two periods until the revolution of IFRS under the hypothesis that the expectations are realised.

First, the data in the nineteenth century: They are as shown by the following figures:

- $\quad$ End of period 1: Loss 1000

- $\quad$ End of period 2: Profit 1331

What are the accounting principles conducting to these astonishingly contrasted figures in the middle of nineteenth century? At that time there is a domination of accounting by commercial and penal lawyers, and, on their part, as protectors of creditors, a general fear for a possible bankruptcy that will endanger the situation of their favourites. These lawyers have inferred from that fear some rules of accounting based on a very pessimistic and very prudent hypothesis of a probable failure of the firm. This hypothesis of failure has led them to value the assets on the basis of liquidation exit market values and to conceive and adopt the famous principle of prudence according to which all potential losses are systematically recorded while potential profits are not recorded. This explains why at the end of the first 
period a huge loss of 1000 is registered: Possibly, trees could be destroyed by a tempest or other accidents so that the whole investment is judged to be lost. If, fortunately, things turn well, as we will here suppose, there will be on the contrary a huge profit of 1331 at the end of the second period when sales arrive.

The question is to explain how such a an accounting system, that has been named 'static accounting' by German scholars on behalf of its reference to the stopping of the firm, may have been accepted by the capitalists of the time knowing that it generally leads to big initial losses and no distribution of dividends during a large part of the periods following investments? Astonishingly, at first sight, the capitalists of the time have been generally very satisfied with this system and even, in some cases, some of them had exaggerated the liquidation values of their assets to bring them to nil as it is the case in our example. The explanation of this 'mystery' lies in the type of financing that dominated the scene at that time: Self-financing. The nineteenth century, as it is well recognised by scholars, made its growth on the basis of selffinancing without almost no debts, except in rare cases. In this context, dividends for hurried shareholders were a plague and, on the contrary, the pessimistic system of lawyers appeared to be a benediction, as far as it permitted an easy financing of investments before their maturation and a resistance against the appetite of hurried shareholders.

Let us see now the situation in the larger part of the twentieth century. The corresponding figures for our farmer are the following ones:

- $\quad$ End of period 1: Loss 500

- $\quad$ End of period 2: Profit 831

As it appears in the twentieth century the loss in the first period has been reduced to a half in comparison with that of the previous century. Even more, as I will explain it later, if we reason on the basis of a real period of activity, say 20 years, the initial and the subsequent annual losses will be reduced to 50, and if we admit the possibility for the farmer to have some other resources (from crops for example) there were much more chances to distribute every year dividends than it was the case with the ugly nineteenth century system that will always show a huge loss of 1000 at the beginning of the first period.

But why accounting principles have been changed in the course of the twentieth century? This is connected with the evolution of the type of dominant capitalists. In the nineteenth century dominant capitalist were owner-managers with a long-term perspective of business. Hurried shareholders who only wanted to make a short term investment, notably by selling frequently their shares on the stock market, were not important and had no saying on accounting matters: 
This explains why they had to put up with the static accounting in spite of their reluctance to this kind of accounting. But at the end of the nineteenth century, due to the rise of big Joint Stock Companies, they began to get a much more important position in the financing of these companies and to make pressure to get another type of more 'acceptable' accounting which could permit to avoid the ugly massive initial losses of the static accounting. Modern lawyers at their service conceived then a new type of financial accounting: Historical cost accounting (HCA) or, more generally, cost based accounting or in Continental Europe 'dynamic' accounting. The main idea underlying this new type of accounting was to abandon the hypothesis of bankruptcy to make place to the going concern hypothesis, it means an hypothesis along which the firm will be considered to be exempt of failure, except if it is explicitly proven the contrary. With this optimistic view of the firm, assets, up to the time of their sale, will no longer be valued at market liquidation values but at their cost, with however the precision that the costs of fixed assets - like trees - will be systematically depreciated over their estimated period of use in order to retain cash in the firm so as to permit the maintaining of capital. In this accounting system profits will be registered and, hence, only distributed, at the time of real sale. This means that, under this theory, the realisation principle, it means the consideration of realised sales, will be erected to the status of the most important principle while the prudence principle inherited from the static period should theoretically disappear, on behalf of valuing assets at their costs. Thus, by appliance of this theory, the income at the end of period 1 will become a loss of 500 instead of 1000. This reduced loss corresponds to the systematic depreciation of the purchase price of the trees (1000) over two periods. In the same way the income end of period two will be equal to 831 - a figure obtained by deducting the depreciation of 500 for the second year from the actual sales -. If the period had been extended to 20 years the annuals loss will only amount to 50 (1000 divided by 20). Of course with this new type of accounting there were as said before - much more chances of distribution of dividends in period 1 , a situation which could satisfy the hurried shareholders of the time.

Now let us see accounting in the $21^{\text {th }}$ with appliance of the IFRS (IAS 41 first version dated 2001). For this type of accounting the figures for this period beginning at the end of the twentieth century are the following ones:

- Beginning of period 1: Profit 100

- $\quad$ End of period 1: Profit 110

- $\quad$ End of period 2: Profit 121

This new agenda of accounting is marked by two dramatic changes in comparison with the previous ones: First a relatively even profit all the time, and, 
second, even more striking, the possibility to get a profit even without real production at the beginning of the first period when the trees are only at their stage of seeds. This is a good characteristic of the IFRS accounting revolution. The explanation of the mystery deserves some initial socio-economic considerations. In order to satisfy more fully the ever more numerous and mighty hurried shareholders in quest of rapid and regular dividends, some modern accountants have proposed to apply the Fisherian (falsified Hicksian) economic theory of value as derived from the practice of modern stock market players. According to the Fisherian theory the value of an asset is the discounted value of the future services this asset will provide, the rate of discount being an expected normal rate of return. In our example of the fruit tree plantation there is only one future service represented by the sales of 1331 expected at the end of period two. If we admit that the annual normal rate of return for this kind of activity is $10 \%$ we can find the Fisherian value of the trees at the beginning of the period 1 by dividing the flow of future sales 1331 by the discount factor of 1,21 (1,1 square) and obtain the amount of 1100 . With this value there is immediately after the foundation of the firm a profit of 100. It is obvious that this kind of financial accounting is extremely dangerous. If the amount of 100 is considered as a true accounting profit, the firm could borrow immediately after its foundation 100 and distribute it as dividends. The same operation could be done for the profit of 110 at the end of period 1. Of course the risk is that realities differ from expectation, in case of tempests and other damages or of bad economic times, and that the firm will happen to be without cash to reimburse its debt and go bankrupt. This management based on 'hopes' of profits is similar to the one that prevailed during the period of the subprime crisis when people lived in the hope of profits resulting from the rise of the values of their homes or shares. It promotes the practice of fictitious dividends. This type of management is also that of modern finance, a type of management equally based on the Fisherian theory of value. As we will see later the fact that it is gaining ground in the very heart of accounting is extremely worrying. It must be noted that, as shown notably by (Suzuki 2010), the Malaysian planters who were supposed to apply the IAS 41 for palm trees considered this type of accounting as an 'Enron accounting' and led a fight against it to obtain the right to bypass it. But this kind of dangerous valuation remains a basis of other IFRS and is always the credo of the IASB.

We can now resume the lessons from the history of accounting theories and practices as explained in more details in an article ${ }^{1}$ that we have committed in the

1 Richard, Jacques (2014), The dangerous dynamics of modern capitalism (from static to IFRS' futuristic accounting), Critical Perspectives on Accounting. 
journal Critical Perspectives on Accounting. Shareholders, with the development of capitalism after the industrial revolution, are eager and eager to get their profit earlier and they tend to impose financial economics to destroy the prudent initial accounting. There is a kind of accelerated process. This observation, based on accounting history corresponds to the findings of the sociologist Harmut Rosa who speaks of an acceleration of social events in his book Die Beschleunigung. Of course today the fair value exit market value and the actuarial value are not for the while applied by the IFRS to all assets but only a few. However the penetration of fair value is a mark of the third stage of accounting in the twenty-first century and of the dangerous trend of this main tool of capitalism.

\section{Official and real reasons for the evolution towards IFRS}

The official reason generally alleged to by the IASC/IASB to defend the cause of the superiority of the fair value approach in form of exit market values when they exist, or of Fisherian discounted values when there are no market values, is generally that investors need to be informed about the value of firms or, at least, more modestly, the value of some important assets. Exit market values or Fisherian values are indeed representative of future prospects and give precious information to shareholders that want to anticipate the development of firms before deciding to invest. In this respect, historical cost accounting (HCA) is judged to be problematic if not obsolete by reason of seven main flaws that are generally mentioned in every textbook of financial management:

First and foremost, HCA is turned to the past; second, it is biased because of the appliance of the traditional principle of prudence which obliges the accountants to register all potential losses and not potential gains: third, is it unable to take account of inflation by definition because it is 'historical'; fourth, it is not able to treat correctly intangible investments; fifth, HCA is fraud with tax based evaluations; sixth, HCA relies on arbitrary calculations notably for depreciations; and seventh, it does not permit to calculate correctly the performance of firms. Poor HCA! Yet, as we will show all these arguments are debatable if not false.

First, HCA is not only turned to the past if we consider the whole system to which it belongs. HCA is generally conceived as a piece of a dual system of information comprising two elements. The first element of this duality is budgeted accounting to give forecasts for the future and the second one is precisely what is called HCA in a restricted sense. I have spent some time in IBM in the management control department and I know what this complex system is and its 
usefulness. It permits to compare results and forecasts in a systematic way without confusion between realities and dreams like in the case of IFRS. This dual model is much more informative than the IFRS system. It can deal with both past and future data. With this system a shareholder can obtain clear separate information both on the cost of his investment (HCA) and on its potential resale value (budgeted accounting).

Second, HCA is not obligatory biased by the appliance of the principle of prudence. The latter, considered in a strict sense, is not a part of the HCA system, at least from a theoretical point of view. This old principle is a residue of a theory and a practice coming from the middle of the nineteenth century initiated by 'static' lawyers that had a totally different conception of accounting than the promoters of HCA. In the theory of cost based accounting, as best represented by the German Schmidt in 1921, the old principle of prudence has no place. The main principle to be followed, except for the principle of going concern, is the principle of realisation, according to which profits are registered when sales of assets are realised. Thus, before their real sale, all assets are registered at their cost without any impairment for lower exit market prices. This characteristic of the true theory of HCA is an important element. It is the proof that a neutral system of international accounting could have been built on the basis of HCA without the recourse to fair value accounting. It also means that the quality of comparability is to be found as well in HCA as in fair value accounting. The fact that, in practice, HCA - in the twentieth century - was polluted and biased by elements inherited from the old conception of static lawyers has nothing to do with a debate based on theoretical arguments.

Let us consider the third argument along which HCA is unable to take account of inflation. This is a very poor argument. Schmalenbach has shown how a cost based 'dynamic' accounting could take account of general inflation. Schmidt has done the same theoretical work in matter of specific inflation in his famous work about replacement cost accounting, and this well before the rediscovery of these principles by Edwards and Bell. As a matter of fact every system of accounting, whatever cost based or fair value based, has to be corrected in periods of inflation.

It is often said that HCA does take into account intangible investments. It is true that HCA does not take account of the value of intangibles because it refuses, along with the principle of realisation, to take account of expected profits like generated goodwill but it can and, normally, must take account of all accumulated past investment costs notably those of education, advertising and research: This obligation has been notably clearly defended by Fritz Schmidt as early as 1921.

In the same way, HCA is not obligatorily polluted by tax data. It is true that HCA has long been coupled with tax data for historical reasons, but the theory of 
HCA is not based on a fiscal conception as clearly demonstrated again by Schmidt. In matter of practice, history has shown that it is perfectly possible to separate HCA from tax accounting, as it has been done notably very early in the US.

Does HCA rely on arbitrary depreciation? This is the sixth question now. Systematic depreciation of fixed assets is calculated on the basis of expectations. Are these expectations arbitrary? Not at all, if tax accounting is not dominating the scene instead of the true theory of HCA. Are depreciations arbitrary only due to the fact that they rely on forecasted data? But in that case what to say about expected cash flows and rate of discount used for fair value accounting?

It remains the last seventh argument according to which HCA is unable to give a correct view of the returns of the firm. This should be the case because it is alleged that there is no correspondence between the accounting rate of returns and the financial internal rate of return as calculated by financials: This assertion is to be found in every textbook of finance. But it is based on false grounds: This has been clearly demonstrated by scholars like (Kay 1976; Brief \& Peasnell 1995).

On behalf of these developments we can now see that the accusations made against HCA are not grounded on serious elements. HCA - understood in a larger sense as a dualistic system of information - can notably provide not only for past data but also for forecasted data, with the advantage of clearly separating these two kinds of data. Thus, if the question of introducing the IFRS is purely a question of information on future events and/or prices reflecting expectations, there is no problem to conserve HCA. Budgeted balance sheets will even permit, by discounting their corresponding data, to give the expected value of firms, which is not the case of today's IFRS! This is a proof of the superiority of this system.

If fair value accounting in the sense of IFRS is not better than HCA as a system of information, the remaining question now is to explain why IFRS have been preferred instead of HCA? This brings us to another explanation as the official reason for the rise of IFRS. For me the main reason is a material and banal question of dividends. For centuries one of the main purpose of capitalist accounting is the question of measuring income for the sake of distribution of dividends. The study of history of accounting in the nineteenth and twentieth century shows that this question of dividends has been the main trigger for the evolution of accounting passing from the old static to the dynamic (HCA) accounting. Even HCA was a product of hurried shareholders, but it was at that time a kind of intelligent compromise between the interests of these hurried shareholders and the older class of owners' managers in search of long term performance and conservation of the capital invested. My thesis is that today the question is the same with IFRS in 
a context of even bigger pressure of hurried shareholders for immediate and massive dividends. The goal of IFRS is to introduce the registration of future profits in the very heart of accounting so that to mix unrealised results and realised results to enlarge the mass of possible dividends. It is the same goal of enlarged dividends, which explains why the proponents of IFRS want for their 'clients' to suppress the systematic depreciation of fixed assets, notably intangibles. The question of 'better' information is only an excuse: As a matter of fact hurried shareholders do not 'eat' information they eat dividends! This explains why information on future prospects and values was not limited to additional notes. In order to permit the distribution of higher dividends it must be incorporated in the balance sheets.

\section{The main problems with the IFRS and the solutions}

As seen before the first problem with the IFRS is the development of a very dangerous conception of accounting that permits the introduction of expected profits in the concept or real performance. This is the same spirit of anticipation of profits that has fostered the subprime crisis. It leads to a forceful attack against the tools of the systematic conservation of the financial capital. Notably an attack against the definition of capital as a liability: As proven by the new definition of equity the goal is to transform capital into mere assets and the management of firms into only a simple portfolio selection on the part of hurried shareholders. In the same spirit an attack against the concept of systematic depreciation is leaded to permit to the shareholders to withdraw from the firm the whole amount of cash collected in a period without any care for renewing the capital.

The second problem with the IFRS is that they constitute a mixed system. It relies on a mix of theories that has totally blurred the concept of income. As (Schmalenbach 1919) has already explained in the early 1920s and later Tinbergen, it can be demonstrated that when you mix different theories of accounting you take the risk of having a totally unintelligible profit.

The third problem is that the IFRS are - on behalf of today's time and challenges - an obsolete type of accounting. The IFRS indeed only focus - in the best case - on the conservation of the financial capital. We have even shown that, practically, they already endanger the very conservation of this limited type of capital! What to say then about the conservation of other capitals, notably human capital and environmental capital which are not in the agenda of the IASB! In this respect the IFRS are a kind of 'ADD' accounting. ' $A$ ' for acceleration and 
anticipation of profits. The first ' $\mathrm{D}$ ' stands for detaxation by offshoring: There are no systematic rules in IFRS against the practice of transfer pricing. The second ' $\mathrm{D}$ ' stands for the destruction of human and natural capital. Unlike for machines there is no systematic depreciation for human beings and natural resources employed in firms: As already shown by (Kapp 2015) the machineries are better protected than humans and nature! It can be demonstrated that to achieve a genuine integrated accounting and reporting we must extend the basic principles of the traditional HCA to human capital and natural capital (Rambaud \& Richard 2015; Rambaud \& Richard 2016a, 2016b; Richard 2015a, 2015b). Nature and mankind must be treated on the liabilities' side as true capitals to be conserved in the same way as financial capital. In correspondence to this new enlarged vision of capital the use of assets, including human and natural assets, must be measured with the help of a triple depreciation line. This is not the case today and all these voids explain why financial accounting and especially IFRS are an addicted accounting system unable to give an answer to the serious problems of our time. Today, these problems should conduct us not to the rise of IFRS and the fall of HCA but on the contrary to the promotion of a new extended HCA that permits the sustainable development of mankind based on the equal conservation of three capitals.

\section{General conclusion}

The European legislators should urgently organise a debate on these questions and notably the question of environmental accounting to replace the dangerous kind of financial accounting dominating the scene. This debate should be organised in a way to permit all opinions, not only those of the representatives of the IASB, to be expressed in a well-balanced way. The absence of representatives of natural capital and human capital inside the boards of big enterprises and the related absence of representatives of human and natural capital inside the national and international boards for determining the accounting system is a real big problem today. I remember how my colleagues, notably Mr Karthik Ramanna and Mr Shyam Sunder, have insisted on the problem of this representation in a direct and indirect manner. Thus, today, Europe should also make proposals on how to permit the presence of the representatives of other capitals than financial capital at all levels of governance. Until now the representatives of financial capital take the lead today for the questions of accounting. But firms are teams of several capitals. This bias constitutes a major problem of governance in the today's world. It must be solved to change the way management and economy are conceived.

Thank you very much for your attention. 
Acknowledgements: This speech was prepared for and read at the international workshop on "Which accounting regulation for Europe's economy and society?" organised under the auspices of the European Parliament in Strasbourg, on 20 May 2015, in tribute to Mr Jérôme Haas (1963-20014), first chairman of the Accounting Standards Authority of France (ANC).

Funding: This article was organised by the Laboratory of Excellence on Financial Regulation (Labex ReFi), which is supported by PRES heSam under the reference ANR-10-LABX-0095. It benefitted from a French government grant by the National Research Agency (ANR) under the funding program 'Investissements d'Avenir Paris Nouveaux Mondes (Investments for the future Paris - New Worlds) reference ANR-11-IDEX-0006-02.

\section{References}

Kapp, K. W. (2015). Les coûts sociaux de l'entreprise privée. (traduction en français de "Social costs of business enterprise »1950). Paris: Ed Les Petits Matins.

Kay, J. (1976). Accountants too could be happy in a golden age; the accounting rate of profit and the internal rate of return. Oxford Economic Papersnew Series, 28(N3), 447-460.

Brief, R., \& Peasnell, K. V. (1995). Clean surplus. A link between accounting and finance. Garland.

Rambaud, A., \& Richard, J. (2015). Sustainability, Finance and Accounting: From the today's Fisherian-(Falsified) Hicksian perspective to a traditional accounting approach. In Social and Sustainable Finance and Impact Investing Conference (SAID Business School-Oxford).

Rambaud, A., \& Richard, J. (2016a). The Triple Depreciation Line instead of the Triple Bottom Line: Towards a genuine Integrated Reporting. Critical Perspectives on Accounting, 33, 92-116.

Rambaud, A., \& Richard, J. (2016b). Policy paper: Recognising environmental issues in performance measurement ANC (Autorité des Normes Comptables) Paris France.

Richard, J. (2015a). The dangerous dynamics of modern capitalism: From static to IFRS's futuristic accounting. Critical Perspectives on Accounting, 30, 9-34.

Richard, J. (2015b). Refonder l'entreprise, la Société Anonyme et l'intérêt social par la comptabilité environnementale. In Vers un nouveau cadre conceptuel pour la comptabilité internationale? (pp. 175-216). Centre Français de Droit Comparé. Ed Société de législation comparée et Mazars.

Schmalenbach, E. (1919). Grundlagen dynamischer Bilanzlehre. ZfhW, 13J(S.1-50), 65-101.

Schmidt, F. (1921). Die organische Bilanz im Rahmen der Wirtschaft. Leipzig: Gloeckner.

Suzuki, T. (2010). IFRS 41, Plantation and Sustainable Development (2012). 